\title{
The number of competitor species is unlinked to sexual dimorphism
}

\author{
Shai Meiri ${ }^{1 *}$, Amy E. Kadison ${ }^{1}$, Maria Novosolov ${ }^{1}$, Panayiotis Pafilis ${ }^{2}$, Johannes \\ Foufopoulos $^{3}$, Yuval Itescu ${ }^{1}$, Pasquale Raia ${ }^{4}$ and Daniel Pincheira-Donoso ${ }^{5}$ \\ ${ }^{1}$ Department of Zoology, Tel Aviv University, Tel Aviv 6997801, Israel; ${ }^{2}$ Section of Zoology and Marine Biology, \\ Department of Biology, University of Athens, Panepistimioupolis, Ilissia, Athens 157-84, Greece; ${ }^{3}$ School of Natural \\ Resources and Environment, University of Michigan, Ann Arbor, Ann Arbor MI 48109, USA; ${ }^{4}$ Dipartimento di Scienze \\ della Terra, dell'Ambiente e delle Risorse, Università Federico II, L.go San Marcellino 10, Naples 80138, Italy; and \\ ${ }^{5}$ School of Life Sciences, University of Lincoln, Riseholme Park, Lincoln LN2 2LG, UK
}

\begin{abstract}
Summary
1. Sexual size dimorphism (SSD) can allow males and females of the same species to specialize on different sized food items and therefore minimize intraspecific competition.

2. Interspecific competition, however, is thought to limit sexual dimorphism, as larger competitors in the community will prevent the larger sex from evolving larger size, and smaller species may prevent the smaller sex from becoming even smaller.

3. We tested this prediction using data on the sexual size dimorphism of lizards, and mammalian carnivores, on islands world-wide.

4. Because insular communities are depauperate, and guilds are species-poor, it is often assumed that enhanced sexual size dimorphism is common on islands. The intensity of interspecific competition, hindering enhanced dimorphism, is thought to increase with competitor richness.

5. We tested whether intraspecific sexual size dimorphism of mammalian carnivores and lizards decreases with increasing island species richness. We further computed the average sexual dimorphism of species on islands and tested whether species-rich islands are inhabited by relatively monomorphic species. Within families and guilds across carnivores and lizards, and with both intraspecific and interspecific approaches, we consistently failed to find support for the notion that species-poor islands harbour more sexually dimorphic individuals or species.

6. We conclude that either interspecific competition does not affect the sexual size dimorphism of insular lizards and carnivores (i.e. character displacement and species sorting are rare in these taxa), or that the number of species in an assemblage or guild is a poor proxy for the intensity of interspecific competition in insular assemblages.
\end{abstract}

Key-words: Carnivora, character displacement, interspecific competition, intraspecific competition, islands, lizards, species sorting

\section{Introduction}

The study of community assembly ascribes great importance to competition-mediated ecological interactions, as well as to adaptive character displacement by means of competition (Bolnick \& Doebeli 2003; Dayan \& Simberloff 2005; Stuart \& Losos 2013). Community-wide character displacement (Strong, Szyska \& Simberloff 1979) is a pattern whereby species in a guild of competitors adjust their morphology according to that of their competitors.

*Correspondence author. E-mail: uncshai@post.tau.ac.il
It is usually assumed that species of intermediate size (or with intermediately sized trophic apparatuses) evolve a size that approximates the geometric mean of their larger and smaller competitors (Dayan \& Simberloff 1998). Via this process, size ratios between competitors within a guild become equal - so that no guild member too closely resembles any other (Dayan \& Simberloff 2005). This may reduce competition among species belonging to a single guild, assuming that guild members of similar size require similar food items, and provided species in the guild do not avoid competition along different niche axes (i.e. by exploiting different activity times). Standard 
ecological theory, following innovative 1930s laboratory experiments with two species of protists (Gause 1934), still often postulates that species that are too similar in their ecological requirements cannot coexist. Such species can either diverge (often, in size), or the lesser competitor is driven to extinction (Hutchinson 1959; Abrams 1983; Szabo \& Meszena 2006; but see Meiri, Dayan \& Simberloff 2007).

Ecological competition takes place not only between species, but also within them (Darwin 1859; Doebeli 2011). Strong intraspecific competition can select for character divergence between individuals within a population (Bolnick et al. 2003; Scott et al. 2003). Food is usually considered a major factor limiting population sizes, and animal populations, especially on islands, are usually assumed to be near the carrying capacity of the environment (MacArthur \& Wilson 1967). When the sexes compete over food, theory suggests that sexual dimorphism can evolve via frequency-dependent natural selection, enabling males and females to specialize on different foods (Slatkin 1984; Bolnick \& Doebeli 2003). Therefore, strong intersexual competition can lead to selection for accentuated sexual size differences, so that the smaller sex becomes even smaller, and the larger sex increases in size. It is assumed that partitioning available resources between sexes reduces intraspecific competition (Rothstein 1973; Patterson 1983; Shine 1989; Temeles, Miller \& Rifkin 2010; Cooper, Gilman \& Boughman 2011). Sexual segregation of the diet in size-dimorphic species seems to be prevalent in mammalian carnivores (e.g. Erlinge 1983; Birks \& Dunstone 1985; Funston et al. 1998; Zielinski et al. 1999; McDonald 2002), but empirical support for its presence in lizards is equivocal (cf. e.g. Schoener 1967; Schoener, Slade \& Stinson 1982; Shine 1989; Perry 1996; Herrel, Van Damme \& De Vree 1996; Herrel et al. 1999; Kalboussi \& Nouira 2004; Hibbits et al. 2005).

Sexual dimorphism may initially evolve as a consequence of either natural selection, sexual selection (e.g. Gittleman \& Van Valkenburgh 1997) or fecundity selection (selection for larger females to enlarge brood size or offspring size, e.g. Scharf \& Meiri 2013). Selection driven by intersexual competition will enhance these size differences to minimize resource overlap (Shine 1989; Dayan \& Simberloff 1994).

Sexual size dimorphism (SSD) is often assumed to be more likely to evolve where intraspecific competition is fierce, but interspecific competition, which can prevent the sexes from diverging, is weak (e.g. Greenberg \& Olsen 2010; Cooper, Gilman \& Boughman 2011; Luther \& Greenberg 2011). Because islands are often species-poor, many insular guilds are depauperate, so that an insular population is often faced with fewer competitor species than an equivalent mainland population. This has led to the common assumption that insular populations often face weaker interspecific competition (Scott et al. 2003; Luther \& Greenberg 2011; Ballentine et al. 2013). Additionally, the often very high densities of animals in insular populations (e.g. MacArthur, Diamond \& Karr 1972; Case 1975; Rodda et al. 2001; Novosolov, Raia \& Meiri 2013) can lead to strong intraspecific competition on islands (e.g. Melton 1982; Adler \& Levins 1994; Raia \& Meiri 2006; Pafilis et al. 2009), selecting for increased SSD.

Sexual size dimorphism is often higher on islands than it is in mainland areas (e.g. Selander 1966; Ebenman \& Nilsson 1982; Dayan \& Simberloff 1994; Simberloff et al. 2000; Pearson, Shine \& How 2002; Olson \& Turvey 2013). This enhanced SSD on islands is viewed as one way for insular populations to expand their niches (the niche variation hypothesis, Van Valen 1965; Meiri, Dayan \& Simberloff 2005a). Under this hypothesis, morphological variability, often expressed as enhanced SSD, is greater in populations with wider niches. This has often been tested by comparing variability within insular and mainland populations, assuming that the former have wider niches (or higher SSD) because of reduced interspecific competition. Variability, in general, and sexual size dimorphism specifically, are often hypothesized to decline as the number of competitors increase (e.g. MacArthur \& Wilson 1967; p121; Roughgarden 1974; Butler, Sawyer \& Losos 2007; Losos 2009). Thus, low richness is thought to lead to increased variability, adaptive polymorphisms, and especially, to high sexual dimorphism of insular populations (Dayan \& Simberloff 1998; Landry \& Lapointe 2001; Greenberg \& Danner 2013; but see Dobzhansky 1937; Kinsey 1937; Raia, Barbera \& Conte 2003; Raia et al. 2010). It is not at all clear, however, whether insular populations, or populations from species-poor environments, are generally more variable (reviewed in Meiri, Dayan \& Simberloff 2005a), or more sexually dimorphic (Dunham, Tinkle \& Gibbons 1978; Blondel et al. 2002; Meiri, Dayan \& Simberloff 2005a; Pafilis et al. 2009) than species from the mainland or from species-rich communities.

The intensity of interspecific competition is thought to increase with the number of competing species in a community (Soule 1966; Rising 1988; Bolnick \& Doebeli 2003; Mesquita, Colli \& Vitt 2007; Losos 2009; Parent \& Crespi 2009; Laube, Graham \& Bohning-Gaese 2013; cf. Pianka 1974). Even in a closely knit guild of ecologically similar species, however, richness may be a poor indicator for the selection pressure faced by individuals in a particular population (Dunham, Tinkle \& Gibbons 1978; Meiri, Dayan \& Simberloff 2005a). It may well be that a focal species 'feels' only the competition from the species adjacent to it in size, whereas much larger or smaller species are not direct competitors (Meiri, Dayan \& Simberloff 2007). In fact, the removal of a large predator in a guild can result in reduced competition pressure on a smaller competitor (meso-predator release effect; Litvaitis \& Villafuerte 1996; Ritchie \& Johnson 2009). The widespread extirpation of wolves (Canis lupus) in the United States, for example, has allowed the proliferation of a meso-predator in the form of the coyote (C. latrans), which, in turn, led to a decrease in the abundance of even smaller guild 
members (kit and swift foxes, Vulpes macrotis and V.vel$o x$, respectively; e.g. Ralls \& White 1995; Kitchen, Gese \& Schauster 1999). In this example, lowering guild richness reduced competition pressure for one species (the coyote), but increased competition pressure on two others (the foxes).

Here, we use global-scale data on lizards and mammalian carnivores on islands that differ in their species richness, to test the hypothesis that sexual size dimorphism decreases with increasing number of competitor species (Rising 1988; Ganeshaiah et al. 1999; Bolnick \& Doebeli 2003; Losos 2009), both at the inter- and intraspecific levels.

\section{Materials and methods}

We use two approaches, two taxa and four data sets to examine the effects of species richness on the degree of sexual size dimorphism (SSD) of insular mammalian carnivores (Carnivora, Bowdich 1821) and lizards. In the first approach, we examine the degree of intraspecific dimorphism in the same species across multiple islands that differ in their community composition. The second, interspecific approach, involves deriving complete species lists for islands, and calculating an index of sexual dimorphism for each island, which is the average dimorphism of all species that inhabit it. Here, because intraspecific data on SSD are unavailable for many island populations, we use a single, averaged value of SSD per species across all the islands it inhabits (see below). The second approach is based on individual species biology, and seeks to test whether SSD decreases with increased competitor number. Thus, using this interspecific approach, we focus on community composition rather than on evolution: we test whether highly dimorphic species tend to be under-represented in species-rich communities. We do this by examining the mean SSD across all species inhabiting an island, then comparing this mean value across islands that differ in their species richness. This is a test of the prediction that species-rich islands are inhabited, on average, by relatively monomorphic species, whereas species-poor islands are inhabited by more dimorphic species.

\section{CARNIVORES}

In the first data set, we quantify body size and SSD using carnivore upper carnassial measurements, taken by one of us (SM, $87 \%$ of specimens) and by two colleagues (Tamar Dayan and Dan Simberloff, $8 \%$ and $5 \%$ of specimens, respectively), mainly for the purpose of examining the evolution of body size on islands (e.g. Meiri, Dayan \& Simberloff 2004; Meiri, Cooper \& Purvis 2008). Carnivore specimens were measured in natural history museums (Appendix S1, Supporting information) using digital callipers to a $0 \cdot 01-\mathrm{mm}$ precision. We only use data on wild-caught, sexed specimens, with fully erupted carnassials, to calculate SSD (mean carnassial length of the larger sex divided by mean carnassial length of the smaller sex). We record the island from which each specimen originated according to the specimen labels and museum data bases. Populations that were introduced to islands in historic times were omitted.

We use the anterior-posterior length of the upper carnassial tooth as a measure of size. This tooth is selected for several reasons: carnivore carnassial teeth are directly involved in prey processing (e.g. Dayan et al. 1992) and have been shown to respond to the presence of guild members and closely related species (Dayan et al. 1992; Davies et al. 2007). Carnassials are readily available in natural history museums that usually keep only the skulls (and skins) of large mammals. Skull size may be an inferior index of prey-based competition in carnivores, because it is not under direct selection for the size of common prey (Dayan et al. 1989, 1992). Furthermore, the upper carnassials erupt before adulthood, when the skull has not yet reached its adult size. By using carnassial measurements, we can therefore include subadult specimens with adult-sized teeth. While carnivore canine teeth are also selected to respond to prey size (Dayan et al. 1989; Meiri, Simberloff \& Dayan 2011), canines are often fractured, broken or missing altogether from museum specimens (SM, personal observation), and the use of carnassials thus allows us to increase sample sizes. To make sure that our choice of morphological parameter does not influence the results of our analyses, we conducted preliminary analyses with skull and canine measurements. The results were qualitatively the same as those obtained with carnassials (not shown), and we are thus confident that the use of carnassials does not bias our conclusions.

Measures of SSD were extensively reviewed by Smith (1999). Smith recommended the use of the $\log (\mathrm{M} / \mathrm{F})$ or a two-step ratio: $\mathrm{M} / \mathrm{F}$ when $\mathrm{M}>\mathrm{F}$, and $2-\mathrm{F} / \mathrm{M}$ when $\mathrm{F}>\mathrm{M}$. However, because the assumption that high SSD reduces intraspecific competition is independent of the direction of SSD (i.e. of whether males or females are the larger sex), we chose to only focus on the magnitude of dissimilarity between the sexes. Therefore, we use a common measure, the ( $\log _{10}$-transformed) ratio between the sizes of the larger and smaller sex, of the degree to which one sex is larger than the other (e.g. we treat species with females $10 \%$ larger than males as equal to a species in which males are $10 \%$ larger than females) in all analyses. In the interspecific analyses of both lizards and carnivores, and in intraspecific lizard analyses, variability in SSD decreased from species-poor islands to species-rich ones (see below). We therefore use Kendall's tau rank correlation tests in the interspecific analyses (using OLS regression did not result in obtaining stronger support for negative SSD/richness relationships, results not shown). All statistical tests were carried out in R (R Development Core Team 2013).

\section{Intraspecific analyses}

Our intraspecific data set contains measurements of 5220 specimens belonging to 54 species of carnivores inhabiting 123 islands world-wide (2-34 islands per species, introduced species were omitted). We have compiled comprehensive lists of carnivore species on these islands (Appendix S2, Supporting information) to extract the number of carnivores, guild members and family members for each island and each species.

For each of these 54 species, we measured the sizes of males and females in multiple insular populations and computed islandspecific SSD scores. We then regressed, for each species in turn, the per-island scores against the number of its putative competitors on each island.

We took three approaches to designate competition: (i) all carnivore species native to the island (data on the number of native carnivore species is from Meiri, Dayan \& Simberloff 2005b and from museum records); (ii) all members of the same family of the focal species (e.g. Canidae, Felidae; taxonomy follows Wilson \& Mittermeier 2009) and (iii) all guild members. We followed the approach of Dayan et al. $(1989,1992)$ in assigning guild 
membership according to the killing method and limb morphology. We assigned each species into one of eight guilds: badgers, bears, cats, dog/ground civets, mustelids/herpestids, otters, palm civets and raccoons (see Appendix S3, Supporting information for details about which species were assigned to which guild). We then regressed the SSD score of each species in turn against the richness of: (i) all carnivores; (ii) family members; (iii) guild members on all the islands we had data for. We did not analyse guilds and families when richness did not vary (e.g. we regressed grizzly bear SSD score against carnivore richness on the seven islands for which we had data, but not against family and guild richness, because on all these islands the grizzly was the sole ursid, and sole member of the bear guild). In some instances, guilds were identical to families (i.e. the bear and raccoon guilds are identical to the Ursidae and Procyonidae families, respectively).

\section{Interspecific analyses}

Based on the measurements we described above, we created a single-species-specific SSD index by pooling all data for females and males from all measured specimens. We then calculated the mean SSD of all carnivore species on each island for which we had a comprehensive carnivore list. Four islands were omitted because we had no measurements of female Mustela lutreolina (Java and Sumatra), Galidictis grandidieri (Madagascar) and Procyon pygmaeus (Cozumel), and therefore could not calculate SSD for these species. We used Java and Sumatra in analyses of guilds and families that do not include M. lutreolina. Additionally, we computed a mean SSD value for each carnivore family, and each carnivore guild (as defined above) on each island. We then regressed the mean island SSD score against island species richness, mean family SSD score against the richness of family members, and mean guild SSD score against richness of guild members.

Guilds membership is obviously correlated with phylogeny, meaning that closely related species tend to belong to the same guild. We take phylogenetic history directly into account by regressing SSD against: (i) phylogenetic species variability (PSV) and (ii) phylogenetic species richness (PSR). PSV is a richnessindependent phylogenetic diversity metric based on the expected phylogenetic covariance of related taxa (Helmus et al. 2007; Helmus \& Ives 2012). PSV scales in between 0 and 1 (with higher values meaning lower relatedness). PSR is the product of PSV times the (carnivore) species richness of the focal island. If competition affects SSD negatively, we expect PSV and PSR to show a negative relationship with the mean SSD per island. PSV and PSR were computed under R environment by using the package picante (Kembel et al. 2010).

The phylogenetic distance metrics are taken from a carnivore tree which computed as the consensus tree over 100 published carnivore molecular phylogenies (10ktree project, available at http://10ktrees.fas.harvard.edu/, Arnold, Matthews \& Nunn 2010). The tree misses some insular species that we add a posteriori. In particular, we place the striped hog-nosed skunk (Conepatus semistriatus) in polytomy with the two additional Conepatus species in the tree. We also place Hose's palm civet Diplogale hosei, one of the least known carnivore species as sister to the banded palm civet Hemigalus derbyanus (Yasuma 2004). Malagasy falanouc Eupleres goudotii is placed basal to Euplerinae (Yoder et al. 2003). Finally, the recently extinct sea mink Neovison macrodon is placed as sister species to the American mink (Wozencraft 2005).

\section{LIZARDS}

As with carnivores, we use two data sets for lizards: (i) intraspecific - island-specific SSD score of a species is regressed against competitor number on islands and (ii) interspecific - single-species-specific SSD indices are used to create island-specific mean SSD scores, which are regressed, in turn, against species richness on each focal island.

\section{Intraspecific analyses}

These analyses are based on measurements taken by four of us (PP, JF, SM and YI) across populations of three lizard species: the lacertids Podarcis erhardii and P. gaigeae, and the gecko, $M e-$ diodactylus kotschyi, inhabiting many islands in the Aegean Sea, Greece. All animals were captured in accordance with Hellenic National Law (Presidential Decree 67/81). We used snout-vent length (SVL) as a measure of size, and measured specimens in the field and in natural history museums. While head measurements would have probably given a more direct index of food size, and hence of competition for resources, SVL is readily available for all species, whereas head and jaw lengths are scarce (Meiri 2008). Sex was determined by examining primary and secondary sexual characteristics (i.e. the presence of femoral pores, hemipenises, etc.). All specimens were caught in similar habitats: the arid Mediterranean scrubland (phrygana) that dominates most Aegean islands. Podarcis lizards are among the most widespread and abundant diurnal reptiles on the Greek islands and can be found even on tiny islets (Valakos et al. 2008). Larger islands harbour more diverse herpetofaunas, which often include other lacertids (e.g. Lacerta trilineata, much larger than Podarcis), and geckos, as well as skinks, agamas, anguids and snakes.

We used the $\log _{10}$-transformed ratio of the SVL of the larger sex divided by that of the smaller sex on each island as our index of SSD and regressed it against: (i) the number of (other) squamate species on each island; (ii) the number of lizard (Sauria) species (co-existing with Podarcis) on each island. We also tested whether SSD of Podarcis is affected by the presence or absence of the only other lacertid species (the Balkan green lizard, Lacerta trilineata) inhabiting some of these islands by comparing Podarcis SSD on islands with or without the green lizard using a Mann-Whitney $U$ test. We run similar tests to see whether SSD of Mediodactylus kotschyi is affected by the presence of the only other gecko inhabiting the study islands: the Turkish house gecko, Hemidactylus turcicus.

\section{Interspecific analyses}

We obtained comprehensive species lists of lizards on 871 islands world-wide from the literature and from museum data bases (see source lists in Meiri 2008; Novosolov \& Meiri 2013). These islands are inhabited by 312 lizard species (lizard taxonomy follows the April 2013 version of the reptile data base, Uetz 2013), with richness values ranging between 1 and 34 native lizard species per island. We further used these literature sources and museum data as well as some of our own measurements of lizards in museums and in the field, to obtain body sizes for males and females of lizard species. We then calculated species-specific SSD values (Appendix S4, Supporting information).

Lizard sizes are usually reported in one of the five ways: (i) specimen measurements (from which one can calculate means); 
(ii) means; (iii) size ranges; (iv) only maximum size (this is probably the most common measure, Meiri 2008); (v) more rarely, only size minima (minimum size of reproductive female and males) are given, without sizes of larger specimens. To calculate species' SSD scores, we preferentially used means [i.e. options (i) and (ii)] If we had data on both maxima and minima but no data on means we used range midpoints: (size of the largest specimen + size of the smallest adult)/2. We used size maxima only when we could not use either means or range midpoints.

To ensure that the measure of SSD did not bias our results, we ran two types of preliminary analyses (not shown): first, we computed all three (means, midpoints and maxima) pairwise regressions of the three SSD measures for species for which we had SSD data based on at least two measures (e.g. a regression of SSDs based on mean sizes vs. SSDs based on midpoint sizes of the same species). We found that each of the indices was an unbiased estimator of the other two (slope $\approx 1$, intercept $\approx 0$ ). In our second preliminary analysis, we used each size measure separately to calculate SSD and ran our analyses as we did afterwards using the complete data set. Our results were robust to the type of size measure we used to calculate SSD: we obtained qualitatively similar results when we used a reduced set of species for which we have data on SSD based on SVL means only, midpoints only or maxima only.

Similar to the carnivore interspecific analyses, we used the SSD values to obtain island-specific SSD means for lizards in general, and for each lizard family. We then regressed these island-specific mean SSD values on total lizard species richness on the same island, and on the total squamate species richness on the same island, and repeated this for each lizard family in turn.

We then divided lizards into guilds based on their activity patterns, diet and microhabitat use. For this we classified lizards as: (i) diurnal or nocturnal; (ii) carnivorous or herbivorous; (iii) fossorial, terrestrial, arboreal or saxicolous. We considered each combination of the three traits a distinct guild, and regressed the mean SSD of guild members on each island against the number of guild members on the island. Species that are active during both day and night, omnivorous species and those active in multiple microhabitat were counted as members of different guilds as appropriate, in keeping with their habits (e.g. omnivores were analysed in both the herbivorous and carnivorous species guilds, cathemeral species were analysed in both the diurnal and nocturnal guilds, see Appendix S4, Supporting information).

With carnivores, we supplemented the analyses with a regression of SSD vs. phylogenetic distance metrics per island. This was unfeasible with lizards, given no comprehensive (and dated) phylogeny is available for this group.

\section{Results}

\section{CARNIVORES}

\section{Intraspecific analyses}

The SSD of only two of 54 carnivore species (the grey wolf, Canis lupus and the island fox Urocyon littoralis, on 11 and six islands, respectively) is significantly correlated with carnivore richness of the islands they inhabit. The SSD of both species increases with species richness (wolf: slope $=0.003 \pm 0.001, \quad t=2.279, \quad P=0.049, \quad R^{2}=0.366$; fox: slope $\left.=0.005 \pm 0.001, t=3.423, P=0.027, R^{2}=0.746\right)$, opposite to the prediction that SSD is lower in competitorrich environments. Of the 54 slopes we computed (Appendix S5a, Supporting information), only 23 are negative. Of 17 slopes where we had data for at least six insular populations, 10 are negative, not different than the $50 \%$ expected by chance (binomial test, $P=0.629$ ). Thus, low statistical power does not seem to be the reason why we failed to find negative associations.

Three out of 41 carnivore species exhibit a significant association between SSD and the species richness within their guilds. SSD of Lutra lutra (across seven islands) decreases with increasing guild richness, whereas the SSD of the leopard, Panthera pardus (across three islands), and wolf, Canis lupus (across 11 islands), increases with increasing richness (see Appendix S5b, Supporting information for parameter estimates of the regressions of all species). Of 41 slopes (Appendix S5b, Supporting information), 19 are negative. Of 11 slopes where we had data for at least six insular populations, eight were negative, not significantly different than expected by chance (binomial test, $P=0 \cdot 22$ ).

Three of 43 carnivore species exhibit a significant association between SSD and the species richness within their families. For the wolf and leopard, the statistics are similar to those in the former analyses (the guilds and families are identical in their case, Appendix S5c, Supporting information). The SSD of the American marten (Martes americana, across nine islands) significantly decreases with family member richness (slope $=-0.003 \pm 0.001$, $t=-2.444, P=0.045, r^{2}=0.461$. See Appendix S5c, Supporting information for parameter estimates of the regressions of all species). Of 43 slopes, 21 are negative. Of 15 slopes where we had data for at least six insular populations, 10 are negative, not significantly different than expected by chance (binomial test, $P=0 \cdot 30$ ).

\section{Interspecific analyses}

We analysed a data set of 459 islands inhabited by 126 carnivore species (island carnivore richness range: 1-24). The mean SSD of species is significantly and positively correlated with species richness (Kendall tau 0.251, $P<0.0001$, Fig. 1. Data in Appendix S6a, Supporting information), contradicting the prior hypothesis. The amount of variance explained by an OLS regression, however, is only $2.3 \%$ (slope $0.0007 \pm 0.0002$ ), which we take to indicate there is little biological significance to this relationship.

In four of the eight carnivore guilds in our data set (the badger, cat, mustelid-herpestid and otter guilds), SSD is significantly correlated with the number of guild members across islands. In all four guilds, mean SSD is higher on islands having more guild members (Table 1a, Appendix S6b, Supporting information). Within three of the seven families, mean SSD of insular species was significantly correlated with carnivore species richness on the islands 


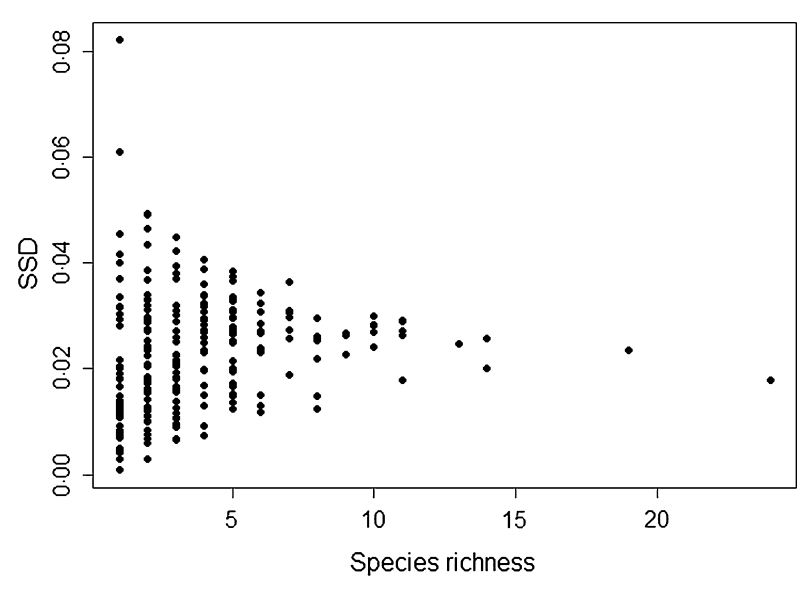

Fig. 1. Mean SSD of carnivore species on islands vs. carnivore species richness on those islands.

(Table 1b, Appendix S6c, Supporting information), although the relationship is marginally non-significant for Viverridae $(P=0.056)$. The correlation between SSD and richness is positive in all these cases, contradicting our prediction.

The relationship between phylogenetic species variability and SSD is non-significant (slope $=1.58, t=1.131$, $P=0.259$ ). Similarly, the relationship between SSD and phylogenetic species richness (the product of PSV and species richness) is non-significant (slope $=21 \cdot 31$, $t=1 \cdot 551, P=0 \cdot 122)$.

Table 1. Island carnivores: regressions of mean sexual size dimorphism of (a) guild members on islands vs. the number of guild members on these islands, (b) family members on islands vs. the number of family members on these islands

(a)

\begin{tabular}{lclll}
\hline Guild & $\begin{array}{l}\text { Kendall } \\
\text { tau }\end{array}$ & $P$ & $\begin{array}{l}\text { Richness } \\
\text { range }\end{array}$ & $\begin{array}{l}n \\
\text { (islands) }\end{array}$ \\
\hline Badger & 0.358 & 0.006 & $1-2$ & 52 \\
Bear & -0.07 & 0.511 & $1-2$ & 89 \\
Cat & 0.286 & 0.004 & $1-7$ & 79 \\
Dog/ground civet & 0.037 & 0.480 & $1-4$ & 301 \\
Mustelids/herpestid & 0.217 & 0.00003 & $1-7$ & 299 \\
Otter & 0.223 & 0.003 & $1-5$ & 172 \\
Palm civet & 0.139 & 0.153 & $1-5$ & 108 \\
Raccoon & 0.228 & 0.105 & $1-3$ & 69 \\
\hline
\end{tabular}

(b)

\begin{tabular}{lcllc}
\hline Family & Kendall tau & $P$ & Richness range & $n$ (islands) \\
\hline Canidae & 0.001 & 0.982 & $1-4$ & 243 \\
Felidae & 0.287 & 0.004 & $1-7$ & 78 \\
Herpestidae & -0.231 & $0 \cdot 191$ & $1-4$ & 25 \\
Mustelidae & 0.112 & 0.015 & $1-6$ & 353 \\
Procyonidae & 0.228 & $0 \cdot 105$ & $1-3$ & 69 \\
Ursidae & -0.07 & 0.511 & $1-2$ & 89 \\
Viverridae & 0.152 & 0.056 & $1-9$ & 126 \\
\hline
\end{tabular}

\section{LIZARDS}

\section{Intraspecific analyses}

The sexual size dimorphism of Podarcis erhardii (Appendix S7a, Supporting information) is uncorrelated with the number of other lizard or squamate species across the 51 islands we examined (Fig. 2a). Similarly P. erhardii SSD does not differ on islands with or without $L$. trilineata, its closest relative and putative competitor (Table 2, Appendix S7, Supporting information; Fig 1a). Equally, SSD is uncorrelated with these predictors for P. gaigeae (although results are marginally non-significant, Table 2, Appendix S7 (Supporting information); Fig. 2b) as well as for Mediodactylus kotschyi (Table 2, Appendix S7, Supporting information; Fig. 2c).

\section{Interspecific analyses}

Across the 871 islands in our data set, no significant correlation was found between insular lizard richness and sexual size dimorphism (Kendall tau $=0.014, P=0.405$, Fig. 3). In six of 12 guilds, the relationship between richness and SSD was significant. SSD decreased with lizard richness, as expected, in four guilds, and increased in two. There was no significant association between SSD and richness in the other six guilds, which include those guilds where species richness on islands attains the highest values (Table 3a). Five of 13 families showed significant correlation between richness and SSD. SSD decreased with lizard richness, as expected, in the Scincidae, but increased with species richness in four families (Dactyloidae, Gekkonidae, Leiocephalidae and Phrynosomatidae, Table 3b). SSD was uncorrelated with richness within the other eight families in our data set (Table 3, Appendix S4b, Supporting information).

\section{Discussion}

We provide the first large-scale test of the long-held hypothesis that sexual dimorphism correlates negatively with the numbers of heterospecific competitors in an assemblage (Soule 1966; MacArthur \& Wilson 1967; Roughgarden 1974; Butler, Sawyer \& Losos 2007). This hypothesis stems from the assumption that natural selection arising from intraspecific competition promotes increased divergence between males and females of the same species, to reduce niche overlap between the sexes. Competition with other species is assumed to limit intersexual divergence, because the smaller sex will approach the morphology of the smaller competitor, and the larger sex will approach the size of the larger heterospecific competitor (Slatkin 1984; Bolnick \& Doebeli 2003; Butler, Sawyer \& Losos 2007). Theory further predicts that the saturated niche space in diverse species assemblages will limit immigration of highly dimorphic taxa (Butler, Sawyer \& Losos 2007). 

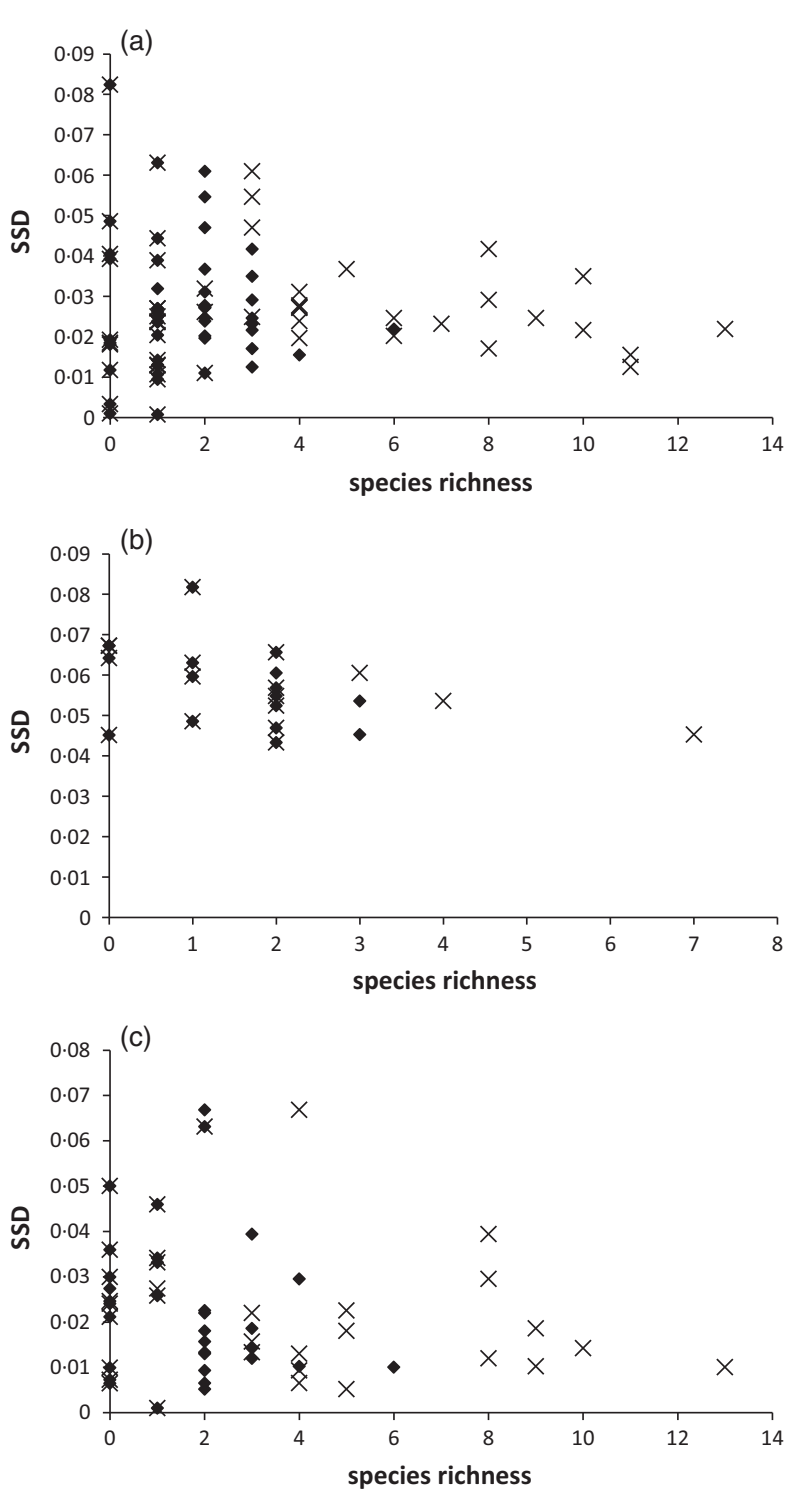

Fig. 2. Sexual size dimorphism of (a) Podarcis erhardii; (b) Podarcis gaigeae and (c) Mediodactylus kotschyi vs. the number of lizard species (diamonds) and squamate species (x symbols) on islands in the Aegean Sea.
We analysed data for 1505 island assemblages populated by 126 carnivore and 362 lizard species, at both intra- and interspecific levels. In general, our results are opposed to the prediction that SSD declines on speciesrich islands. Across both groups of organisms, and using both approaches, our data did not support the notion that species richness has any consistent relationship with sexual size dimorphism. The variance of SSD scores declines with richness. On species-poor islands SSD can vary greatly, whereas the SSD on species-rich islands tends towards a medium value (e.g. Figs 1 and 3). Both the richest islands and single-species islands have extremely dimorphic species. In carnivores, for example, we found that the richest islands (Borneo, Sumatra - the latter not analysed because we have one species without data for females, see above) are both inhabited by the least dimorphic insular species (Lutrogale perspicillata). Sumatra, the richest island, is inhabited by the fourth most dimorphic carnivore species occurring on islands (Neofelis diardi). The most dimorphic insular carnivores, Melursus ursinus and Mustela itatsi, inhabit the rich islands of Sri Lanka (14 species) and Honshu (10 species), respectively. The same is true for single-species islands: L. perspicilatta occurs on single-species islands and so does the most dimorphic carnivore occurring on islands $-M$. itatsi. Similarly, in lizards, the species-rich (24 spp.) Isla de Juventud is inhabited by both the nearly monomorphic Anolis chamaeleonides and by the extremely dimorphic Anolis homolechis (the seventh most dimorphic lizard in our data set). Single-species islands may likewise have extremely dimorphic (e.g. Anolis cooki, ninth most dimorphic of 324 species in our data set, on Cayo Punta Aguila), or nearly monomorphic species (e.g. Sphaerodactylus nigropunctatus, in which females and males are equal in size, inhabiting islands having between 1 and 18 lizard species).

To us this signifies little beyond the fact that there are many more species-poor than species-rich islands, and the range of observed values expands with increasing sample size. Thus, it seems that richness does not exert selection for particular SSD value. Therefore, (1) any SSD value

Table 2. Sexual size dimorphism vs. richness of putative competitors on various islands within three Aegean sea island species

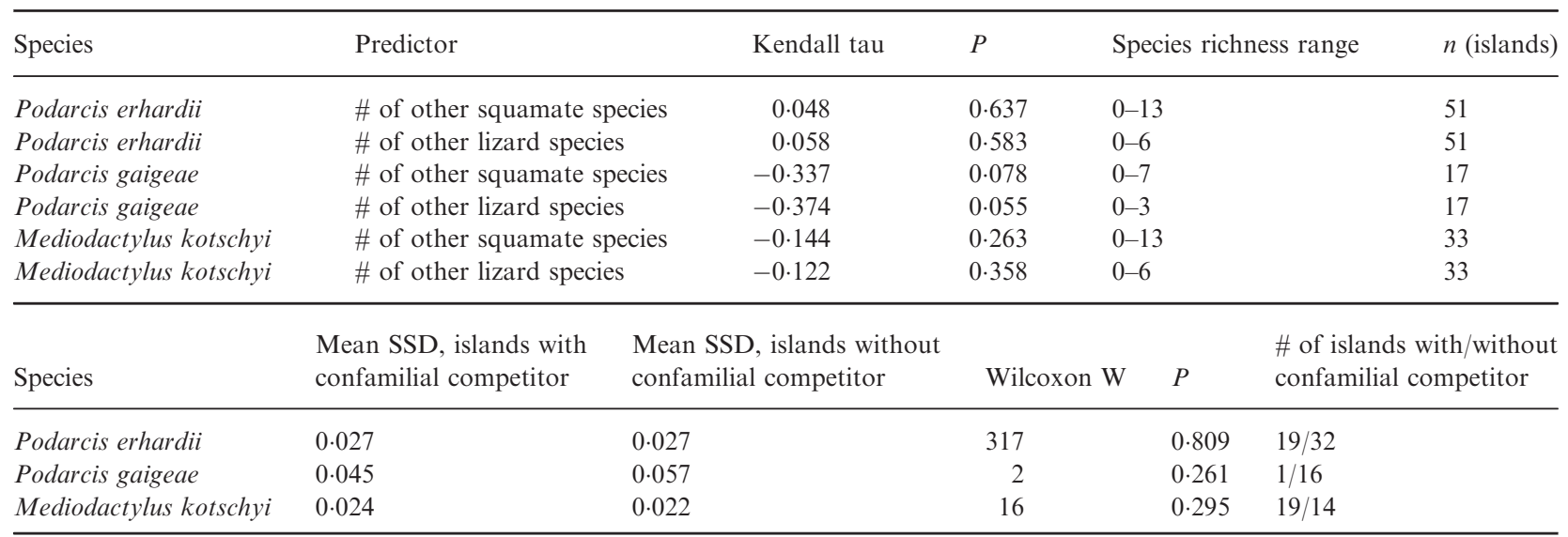

The con-familial competitor is Lacerta trilineata for the two Podarcis species, and Hemidactylus turcicus for M. kotschyi. 


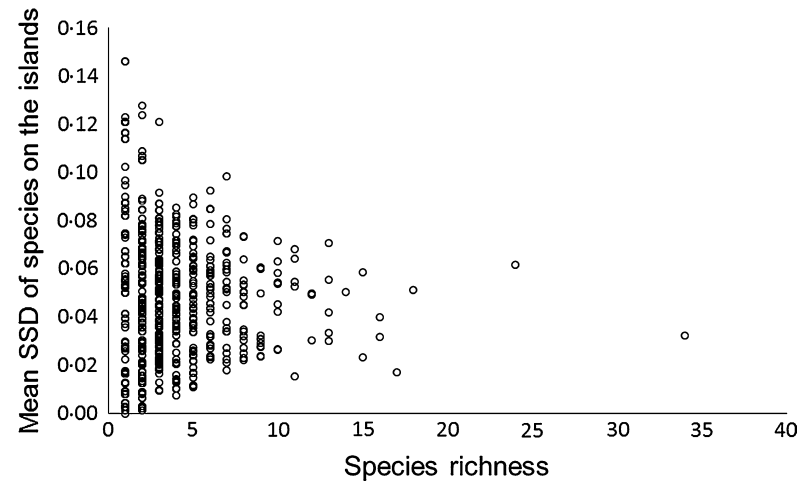

Fig. 3. Mean SSD of lizard species on islands vs. lizard species richness on those islands.

can be observed on species-poor islands and (2) SSD variance across such species-poor islands is, consequently, great. As richness increases, SSD converges towards the mean value across all taxa, and SSD variance across species-rich islands is therefore low.

We found that the predicted negative relationship is not more frequent than the positive relationship, if anything it is somewhat less common. Furthermore, significant associations between SSD and richness are rare. The specific predictions we drew from theory were rarely ever investigated. Stephens \& Wiens (2009) found equivocal support for a negative relationship between SSD and richness in turtles.

Theory predicts that available niche space can be saturated in equivalent ways by multiple monomorphic species or by fewer, ecologically dimorphic species, in which the sexes become equivalent 'ecological units' for niche occupation (Dayan \& Simberloff 1998; Butler, Sawyer \& Losos 2007). Therefore, once available niches have been occupied by either sexes or species, the ecological opportunities for additional taxa to enter a community (via in situ evolution or immigration) are reduced (Butler, Sawyer $\&$ Losos 2007). The rationale of the theory is that more competitors engaged in an assemblage necessarily saturate the available, albeit limited, niche space. Higher numbers of coexisting competitors have been found to entail a predictable decline in the extent of sexual dimorphism across island communities in Anolis lizards (Schoener 1977; Butler, Sawyer \& Losos 2007; Poe, Goheen \& Hulebak 2007; but see our contrasting results for Dactyloidae, Table 3), mainland assemblages of Liolaemus lizards (PincheiraDonoso et al., unpublished), and mammals (Dayan \& Simberloff 1998). However, our large spatial and taxonomic scale study reveals that the predicted pattern is the exception, rather than the generality, and that the inverse relationship is equally common.

There are several ways to interpret our findings. One possibility is that dimorphic sexes and species are not ecologically different units. Although disruptive natural selection has increasingly been suggested to drive sexual dimorphism (Shine 1989; Temeles et al. 2000; Bolnick \& Doebeli 2003; Fairbairn, Blanckenhorn \& Szekely 2007;
Table 3. Regressions of mean sexual size dimorphism of (a) guild and (b) family members on islands vs. the number of guild and family members on those islands. $P$ values $<0.05$ are in boldface

(a) Guilds

\begin{tabular}{|c|c|c|c|c|}
\hline Guild & $\begin{array}{l}\text { Kendall } \\
\text { tau }\end{array}$ & $P$ & $\begin{array}{l}n \\
\text { (islands) }\end{array}$ & $\begin{array}{l}\text { Richness } \\
\text { range }\end{array}$ \\
\hline $\begin{array}{l}\text { Diurnal, Arboreal, } \\
\text { Carnivorous }\end{array}$ & $0 \cdot 018$ & 0.419 & 622 & $1-16$ \\
\hline $\begin{array}{l}\text { Diurnal, Arboreal, } \\
\text { Herbivorous }\end{array}$ & 0.007 & $0 \cdot 867$ & 370 & $1-4$ \\
\hline $\begin{array}{l}\text { Diurnal, Fossorial, } \\
\text { Carnivorous }\end{array}$ & $0 \cdot 000$ & 1.000 & 27 & $1-3$ \\
\hline $\begin{array}{l}\text { Diurnal, Saxicolous, } \\
\text { Carnivorous }\end{array}$ & $-0 \cdot 203$ & $<0.0001$ & 492 & $1-9$ \\
\hline $\begin{array}{l}\text { Diurnal, Saxicolous, } \\
\text { Herbivorous }\end{array}$ & $-0 \cdot 213$ & 0.002 & 133 & $1-3$ \\
\hline $\begin{array}{l}\text { Diurnal, Terrestrial, } \\
\text { Carnivorous }\end{array}$ & $-0 \cdot 016$ & 0.406 & 670 & $1-13$ \\
\hline $\begin{array}{l}\text { Diurnal, Terrestrial, } \\
\text { Herbivorous }\end{array}$ & $0 \cdot 111$ & 0.0003 & 497 & $1-6$ \\
\hline $\begin{array}{l}\text { Diurnal, Semi-Aquatic, } \\
\text { Carnivorous }\end{array}$ & $-0 \cdot 352$ & 0.020 & 37 & $1-2$ \\
\hline $\begin{array}{l}\text { Nocturnal, Arboreal, } \\
\text { Carnivorous }\end{array}$ & -0.036 & 0.328 & 288 & $1-11$ \\
\hline $\begin{array}{l}\text { Nocturnal, Saxicolous, } \\
\text { Carnivorous }\end{array}$ & $-0 \cdot 056$ & $0 \cdot 210$ & 253 & $1-7$ \\
\hline $\begin{array}{l}\text { Nocturnal, Saxicolous, } \\
\text { Herbivorous }\end{array}$ & -1.000 & 0.0001 & 14 & $1-2$ \\
\hline $\begin{array}{l}\text { Nocturnal, Terrestrial, } \\
\text { Carnivorous }\end{array}$ & $0 \cdot 110$ & 0.050 & 165 & $1-4$ \\
\hline
\end{tabular}

(b) Families

\begin{tabular}{|c|c|c|c|c|}
\hline Family & $\begin{array}{l}\text { Kendall } \\
\text { tau }\end{array}$ & $P$ & $\begin{array}{l}n \\
\text { (islands) }\end{array}$ & $\begin{array}{l}\text { Richness } \\
\text { range }\end{array}$ \\
\hline Agamidae & $0 \cdot 132$ & 0.336 & 42 & $1-9$ \\
\hline Anguidae & $0 \cdot 773$ & $-0 \cdot 045$ & 33 & $1-2$ \\
\hline Chamaeleonidae & $-0 \cdot 333$ & 0.564 & 4 & $1-2$ \\
\hline Dactyloidae & $0 \cdot 120$ & $0 \cdot 002$ & 433 & $1-12$ \\
\hline Gekkonidae & $0 \cdot 225$ & $0 \cdot 0001$ & 211 & $1-13$ \\
\hline Iguanidae & $-0 \cdot 062$ & $0 \cdot 312$ & 205 & $1-3$ \\
\hline Lacertidae & 0.078 & $0 \cdot 254$ & 134 & $1-5$ \\
\hline Leiocephalidae & $0 \cdot 281$ & $0 \cdot 0001$ & 154 & $1-5$ \\
\hline Phrynosomatidae & $0 \cdot 226$ & $0 \cdot 047$ & 61 & $1-6$ \\
\hline Phyllodactylidae & 0.006 & 0.949 & 100 & $1-2$ \\
\hline Scincidae & $-0 \cdot 378$ & $<0 \cdot 0001$ & 147 & $1-9$ \\
\hline Sphaerodactylidae & $-0 \cdot 022$ & $0 \cdot 654$ & 290 & $1-4$ \\
\hline Teiidae & $-0 \cdot 042$ & 0.492 & 234 & $1-2$ \\
\hline
\end{tabular}

Doebeli 2011), sexual selection remains the traditional explanation for divergent evolution between sexes (Andersson 1994; Fairbairn, Blanckenhorn \& Szekely 2007). A number of previous studies have shown the prevalent influence of sexual selection on sexual dimorphisms compared with natural and fecundity selection (Kingsolver et al. 2001; Cox \& Calsbeek 2009). Sex-specific selection, arising from competition over mates or from fecundity selection on females, does not necessarily demand intersexual ecological niche divergence. Therefore, sexual dimorphism can evolve with minimal differentiation in ecological niches between the sexes (e.g. Coyne \& Orr 
2004). Thus, even if sexual selection is a major driver of sexual dimorphism in the studied communities, it may have little effect on the ecological opportunities for species recruitment into these assemblages. As a result, SSD and species richness would vary independently from each other across islands.

Alternatively, competition may well influence sexual dimorphism, but the intensity of interspecific competition is not correlated with the number of coexisting species, or even with the number of coexisting guild members (Grant 1968; Pianka 1971; Dunham, Tinkle \& Gibbons 1978; Meiri, Dayan \& Simberloff 2005a). Although the assumption that competition intensifies with increasing species richness is a central one in ecology (Soule 1966; MacArthur \& Wilson 1967; Schoener 1969; Angerbjorn 1986; Hunter \& Caro 2008; Laube, Graham \& Bohning-Gaese 2013; and see above), a lack of a relationship between competitor numbers and sexual dimorphism can arise for multiple reasons. Coexisting species of the same lineage (i.e. mammals, lizards) may differ so much that their ecological needs and habits do not imply reductions in dimorphism, despite size overlap. Fine-scale (e.g. within the same assemblage) spatial or temporal (Kronfeld-Schor \& Dayan 2003) micro-allopatry among coexisting species could prevent ecological competition between them. For example, overlap of the niche space occupied by fossorial and non-fossorial species can be minimal, even if they coexist in the same site. Similarly, strong overlap in multiple dimensions of the niche of coexisting species can be ecologically sustainable, if their daily periods of activity do not overlap (e.g. diurnal vs. nocturnal habits). In principle, guild-specific and, to an extent, family-specific analyses would have meant that we compare species that share similar habitats and activity times. It is likely, however, that our guild allocation is too coarse, and that the family is too inclusive an assembly to accurately estimate the number of actual competitors a species is faced with in its community. In other words, we may have grouped together too many species that do not actually compete, and a stricter guild definition will yield the expected patterns. It is worth noting, however, that using phylogenetic relatedness instead of guild membership gives almost identical insight: SSD is non-sensitive to species richness. Micro-allopatry is yet another possible mechanism that will make our richness data too coarse to be ecologically meaningful, at least on large, spatially heterogeneous islands.

A third alternative is that the strength of actual interspecific competition is seldom linked to species richness. For competition to scale positively with species richness, niche availability across all islands should be relatively similar. However, more complex environments may offer more niches than homogeneous ones. Hence, the same number of coexisting species can result in stronger interspecific competition within the latter relative to the former. This would not explain our lack of negative richness/SSD associations in the intraspecific analyses - especially the lizard associations, where all islands share similar, dominant Mediterranean scrub habitats.

Crucially, the number of species need not be related to competition intensity for other reasons: species-rich (often larger) islands may have a wider resource spectrum (and more diverse habitats, hence more room for micro-allopatry, Hortal et al. 2009), which will allow multiple species to coexist with little competition. The smallest and largest species in species-rich communities may be too different to compete in any ecologically meaningful sense (Meiri, Dayan \& Simberloff 2007). Complex intraguild interactions (see e.g. discussion of mesopredator release, above) may actually lower competition intensity for some species in species-rich communities. Finally, it may well be that resources are not limiting in many insular communities, because of predation from non-guild members (more likely in lizards, but also frequent in carnivores, Palomares \& Caro 1999), cannibalism (Pafilis et al. 2009), and disease.

In summary, we find that species-rich insular communities are not composed of less dimorphic species than species-poor communities. Furthermore, populations of the same species are no more dimorphic on species-poor islands than they are on species-rich islands. We suggest that this derives from species richness, even within guilds, being a poor index of competition intensity, and from the role of competition in shaping morphology being over-emphasized in the present ecological and evolutionary discourse.

\section{Acknowledgements}

We thank Tamar Dayan and Daniel Simberloff for invaluable help with measuring carnivore specimens, and museum collection managers for priceless help during our stay at their collections. We also thank Nicola Anthony, Kostas Sagonas, Kinsey Brock, Colin Donihue and Erez Maze for measuring some of the Podarcis specimens, and for help in the field. We thank Inon Scharf and three anonymous referees for providing valuable insights. This study was supported by the Israel Science Foundation (Grant No. 1005/12, to Shai Meiri) and by the Leverhulme Trust (supporting D. Pincheira-Donoso).

\section{References}

Abrams, P. (1983) The theory of limiting similarity. Annual Review of Ecology and Systematics, 14, 359-376.

Adler, G.H. \& Levins, R. (1994) The island syndrome in rodent populations. Quarterly Review of Biology, 69, 473-490.

Andersson, M. (1994) Sexual Selection. Princeton University Press, Princeton, New Jersey, USA.

Angerbjorn, A. (1986) Gigantism in island populations of wood mice (Apodemus) in Europe. Oikos, 47, 47-56.

Arnold, C., Matthews, L.J. \& Nunn, C.L. (2010) The 10kTrees website: a new online resource for primate phylogeny. Evolutionary Anthropology, 19. 114-118.

Ballentine, B., Horton, B., Brown, E.T. \& Greenberg, R. (2013) Divergent selection on bill morphology contributes to nonrandom mating between swamp sparrow subspecies. Animal Behaviour, 86, 467-473.

Birks, J.D.S. \& Dunstone, N. (1985) Sex-related differences in the diet of the mink Mustela vison. Holarctic Ecology, 8, 245-252.

Blondel, J., Perret, P., Ansett, M.-C. \& Thebaud, C. (2002) Evolution of sexual size dimorphism in birds: test of hypotheses using blue tits in contrasted Mediterranean habitats. Journal of Evolutionary Biology, 15, 440-450.

Bolnick, D.I. \& Doebeli, M. (2003) Sexual dimorphism and adaptive speciation: two sides of the same ecological coin. Evolution, 57, $2433-2449$. 
Bolnick, D.I., Svanbäck, R., Fordyce, J.A., Yang, L.H., Davis, J.M., Hulsey, C.D. et al. (2003) The ecology of individuals: incidence and implications of individual specialization. American Naturalist, 161, 1-28.

Butler, M.A., Sawyer, S.A. \& Losos, J.B. (2007) Sexual dimorphism and adaptive radiation in Anolis lizards. Nature, 447, 202-205.

Case, T.J. (1975) Species numbers, density compensation, and colonizing ability of lizards on islands in the Gulf of California. Ecology, 56, 3-18.

Cooper, I.A., Gilman, R.T. \& Boughman, J.W. (2011) Sexual dimorphism and speciation on two ecological coins: patterns from nature and theoretical predictions. Evolution, 65, 2553-2571.

Cox, R.M. \& Calsbeek, R. (2009) Sexually antagonistic selection, sexual dimorphism, and the resolution of intralocus sexual conflict. American Naturalist, 173, 176-187.

Coyne, J.A. \& Orr, H.A. (2004) Speciation. Sinauer Associates, Sunderland Massachusetts, USA.

Darwin, C.R. (1859) On the Origin of Species by Means of Natural Selection. John Murray, London, UK.

Davies, J.T., Meiri, S., Barraclough, T.G. \& Gittleman, J.L. (2007) Species coexistence and character divergence across carnivores. Ecology Letters, 10, 146-152.

Dayan, T. \& Simberloff, D. (1994) Character displacement, sexual size dimorphism and morphological variation among British and Irish mustelids. Ecology, 75, 1063-1073.

Dayan, T. \& Simberloff, D. (1998) Size patterns among competitors: ecological character displacement and character release in mammals, with special reference to island populations. Mammal Review, 28, 99-124.

Dayan, T. \& Simberloff, D. (2005) Ecological and community-wide character displacement: the next generation. Ecology Letters, 8, 875-894

Dayan, T., Simberloff, D., Tchernov, E. \& Yom-Tov, Y. (1989) Inter- and intraspecific character displacement in mustelids. Ecology, 70, 15261539.

Dayan, T., Simberloff, D., Tchernov, E. \& Yom-Tov, Y. (1992) Canine carnassials: character displacement in the wolves, jackals and foxes of Israel. Biological Journal of the Linnean Society, 45, 315-331.

Dobzhansky, T. (1937) Genetics and the Origin of Species. Columbia University Press, New York, USA.

Doebeli, M. (2011) Adaptive Diversification. Princeton University Press, Princeton, New Jersey, USA

Dunham, A.E., Tinkle, D.W. \& Gibbons, J.W. (1978) Body size in island lizards: a cautionary tale. Ecology, 59, 1230-1238.

Ebenman, B. \& Nilsson, S.G. (1982) Components of niche width in a territorial bird species: habitat utilization in males and females of the chaffinch (Fringilla coelebs) on islands and mainland. American Naturalist, 119, 331-344.

Erlinge, S. (1983) Demography and dynamics of a stoat Mustela erminea population in a diverse community of vertebrates. Journal of Animal Ecology, 52, 705-726.

Fairbairn, D.J., Blanckenhorn, W.U. \& Szekely, T. (2007) Sex, Size \& Gender Roles. Evolutionary Studies of Sexual Size Dimorphism. Oxford University Press, Oxford, UK.

Funston, P.J., Mills, M., Biggs, H. \& Richardson, P. (1998) Hunting by male lions: ecological influences and socioecological implications. Animal Behaviour, 56, 1333-1345.

Ganeshaiah, K.N., Nehru, J., Kumar, A.R.V. \& Chandrashekara, K. (1999) How much should the Hutchinson ratio be and why? Oikos, 87 201-203.

Gause, G.F. (1934) The Struggle for Existence. Williams \& Wilkins, Baltimore, Maryland, USA.

Gittleman, J.L. \& Van Valkenburgh, B. (1997) Sexual dimorphism in the canines and skulls of carnivores: effects of size, phylogeny and behavioural ecology. Journal of Zoology, 242, 97-117.

Grant, P.R. (1968) Bill size, body size, and the ecological adaptations of bird species to competitive situations on islands. Systematic Zoology, 17, 319-333.

Greenberg, R. \& Danner, R.M. (2013) Climate, ecological release and bill dimorphism in an island songbird. Biology Letters, 9, 20130118.

Greenberg, R. \& Olsen, B. (2010) Bill size and dimorphism in tidal-marsh sparrows: island-like processes in a continental habitat. Ecology, 91, 2436.

Helmus, M.R. \& Ives, A.R. (2012) Phylogenetic diversity-area curves. Ecology, 93, S31-S43.

Helmus, M.R., Bland, T.J., Williams, C.K. \& Ives, A.R. (2007) Phylogenetic measures of biodiversity. The American Naturalist, 169, E68-E83.

Herrel, A., Van Damme, R. \& De Vree, F. (1996) Sexual dimorphism of head size in Podarcis hispanica atrata: testing the dietary divergence hypothesis by bite force analysis. Netherlands Journal of Zoology, 46, 253-262.

Herrel, A., Spithoven, L., Van Damme, R. \& De Vree, F. (1999) Sexual dimorphism of head size in Gallotia galloti: testing the niche divergence hypothesis by functional analyses. Functional Ecology, 13, 289-297.

Hibbits, T.J., Pianka, E.R., Huey, R.B. \& Whiting, M.J. (2005) Ecology of the common barking gecko (Ptenopus garrulus) in Southern Africa. Journal of Herpetology, 39, 509-515.

Hortal, J., Triantis, K.A., Meiri, S., Thebault, E. \& Sfenthourakis, S. (2009) Island species richness increases with habitat diversity. American Naturalist, 174, e205-e217.

Hunter, J. \& Caro, T. (2008) Interspecific competition and predation in American carnivore families. Ethology Ecology \& Evolution, 20, 295324.

Hutchinson, G.E. (1959) Homage to Santa Rosalia, or why are there so many kinds of animals? American Naturalist, 93, 145-159.

Kalboussi, M. \& Nouira, S. (2004) Comparative diet of northern and southern Tunisian populations of Chalcides ocellatus (Forskal, 1775). Revista Espanola de Herpetologia, 18, 29-39.

Kembel, S.W., Cowan, P.D., Helmus, M.R., Cornwell, W.K., Morlon, H., Ackerly, D.D. et al. (2010) Picante: R tools for integrating phylogenies and ecology. Bioinformatics, 26, 1463-1464.

Kingsolver, J.G., Hoekstra, H.E., Hoekstra, J.M., Berrigan, D., Vignieri, S.N., Hill, C.E. et al. (2001) The strength of phenotypic selection in natural populations. American Naturalist, 157, 245-261.

Kinsey, A.C. (1937) An evolutionary analysis of insular and continental species. Proceedings of the National Academy of Sciences, United States of America, 23, 5-11.

Kitchen, A.M., Gese, E.M. \& Schauster, E.R. (1999) Resource partitioning between coyotes and swift foxes: space, time, and diet. Canadian Journal of Zoology, 77, 1645-1656.

Kronfeld-Schor, N. \& Dayan, T. (2003) Partitioning of time as an ecological resource. Annual Review of Ecology, Evolution \& Systematics, 34, 153-181.

Landry, P.A. \& Lapointe, F.J. (2001) Within-population craniometric variability of insular populations of deer mice, Peromyscus maniculatus, elucidated by landscape configuration. Oikos, 95, 136-146.

Laube, I., Graham, C.H. \& Bohning-Gaese, K. (2013) Intra-generic species richness and dispersal ability interact to determine geographic ranges of birds. Global Ecology and Biogeography, 22, 223-232.

Litvaitis, J.A. \& Villafuerte, R. (1996) Intraguild predation, mesopredator release, and prey stability. Conservation Biology, 10, 676-677.

Losos, J.B. (2009) Lizards in an Evolutionary Tree: Ecology and Adaptive Radiation of Anoles. University of California Press, Berkeley, California, USA.

Luther, D. \& Greenberg, R. (2011) The island syndrome in coastal wetland ecosystems: convergent evolution of large bills in mangrove passerines. The Auk, 128, 201-204.

MacArthur, R.H., Diamond, J.M. \& Karr, J.R. (1972) Density compensation in island faunas. Ecology, 53, 330-342.

MacArthur, R.H. \& Wilson, E.O. (1967) The Theory of Island Biogeography. Princeton University Press, New Jersey, USA.

McDonald, R.A. (2002) Resource partitioning among British and Irish mustelids. Journal of Animal Ecology, 71, 185-200.

Meiri, S. (2008) Evolution and ecology of lizard body sizes. Global Ecology and Biogeography, 17, 724-734.

Meiri, S., Cooper, N. \& Purvis, A. (2008) The island rule: made to be broken? Proceedings of the Royal Society of London B, 275, 141-148.

Meiri, S., Dayan, T. \& Simberloff, D. (2004) Body size of insular carnivores: little support for the island rule. American Naturalist, 163, 469-479.

Meiri, S., Dayan, T. \& Simberloff, D. (2005a) Variability and sexual size dimorphism in carnivores: testing the niche variation hypothesis. Ecology, 86, 1432-1440

Meiri, S., Dayan, T. \& Simberloff, D. (2005b) Area, isolation, and size evolution in insular carnivores. Ecology Letters, 8, 1211-1217.

Meiri, S., Dayan, T. \& Simberloff, D. (2007) Guild composition and mustelid morphology - Character displacement but no character release. Journal of Biogeography, 34, 2148-2158.

Meiri, S., Simberloff, D. \& Dayan, T. (2011) Community-wide character displacement in the presence of clines: a test of Holarctic weasel guilds. Journal of Animal Ecology, 80, 824-834.

Melton, R.H. (1982) Body size and island Peromyscus: a pattern and a hypothesis. Evolutionary Theory, 6, 113-126.

Mesquita, D.O., Colli, G.R. \& Vitt, L.J. (2007) Ecological release in lizard assemblages of neotropical savannas. Oecologia, 153, 185-195. 
Novosolov, M. \& Meiri, S. (2013) The effect of island type on lizard reproductive traits. Journal of Biogeography, 40, 2385-2395.

Novosolov, M., Raia, P. \& Meiri, S. (2013) The island syndrome in lizards. Global Ecology \& Biogeography, 22, 184-191.

Olson, V.A. \& Turvey, S.T. (2013) The evolution of sexual dimorphism in New Zealand giant moa (Dinornis) and other ratites. Proceedings of the Royal Society B, 280, 20130401.

Pafilis, P., Meiri, S., Foufopoulos, J. \& Valakos, E. (2009) Intraspecific competition and high food availability are associated with insular gigantism in a lizard. Naturwissenschaften, 96, 1107-1113.

Palomares, F. \& Caro, T.M. (1999) Interspecific killing among mammalian carnivores. American Naturalist, 153, 492-508.

Parent, C.E. \& Crespi, B.J. (2009) Ecological opportunity in adaptive radiation of Galapagos endemic land snails. American Naturalist, 174, 898905.

Patterson, B.D. (1983) Grasshopper mandibles and the niche variation hypothesis. Evolution, 37, 375-388.

Pearson, D., Shine, R. \& How, R. (2002) Sex-specific niche partitioning and sexual size dimorphism in Australian pythons (Morelia spilota imbricata). Biological Journal of the Linnean Society, 77, 113-125.

Perry, G. (1996) The evolution of sexual dimorphism in the lizard Anolis polylepis (Iguania): evidence from intraspecific variation in foraging behavior and diet. Canadian Journal of Zoology, 74, 1238-1245.

Pianka, E.R. (1971) Ecology of the agamid lizard Amphibolurus isolepis in Western Australia. Copeia, 1971, 527-536.

Pianka, E.R. (1974) Niche overlap and diffuse competition. Proceedings of the National Academy of Sciences, United States of America, 71, 21412145.

Poe, S., Goheen, J.R. \& Hulebak, E.P. (2007) Convergent exaptation and adaptation in solitary island lizards. Proceedings of the Royal Society of London B, 274, 2231-2237.

R Development Core Team (2013) R: A Language and Environment for Statistical Computing. R Foundation for Statistical Computing, Vienna, Austria.

Raia, P., Barbera, C. \& Conte, M. (2003) The fast life of a dwarfed giant Evolutionary Ecology, 17, 293-313.

Raia, P. \& Meiri, S. (2006) The island rule in large mammals: paleontology meets ecology. Evolution, 60, 1731-1742.

Raia, P., Guarino, F.M., Turano, M., Polese, G., Rippa, D., Carotenuto, F. et al. (2010) The Blue lizard spandrel and the Island Syndrome. BMC Evolutionary Biology, 10, 289.

Ralls, K. \& White, P.J. (1995) Predation on San Joaquin kit foxes by larger canids. Journal of Mammalogy, 76, 723-729.

Rising, J.D. (1988) Geographic variation in sexual dimorphism in size of savannah sparrows (Passerculus sandwichensis) a test of hypotheses. Evolution, 41, 514-524.

Ritchie, E.G. \& Johnson, C.N. (2009) Predator interactions, mesopredator release and biodiversity conservation. Ecology Letters, 12, 982-998.

Rodda, G.H., Perry, G., Rondeau, R.J. \& Lazell, J. (2001) The densest terrestrial vertebrate. Journal of Tropical Ecology, 17, 331-338.

Rothstein, S.I. (1973) Niche-variation model - Is it valid? American Naturalist, 107, 598-620.

Roughgarden, J. (1974) Niche width: biogeographic patterns among Anolis lizard populations. American Naturalist, 108, 429-442.

Scharf, I. \& Meiri, S. (2013) Sexual dimorphism of heads and abdomens: different approaches to 'being large' in female and male lizards. Biological Journal of the Linnean Society, 110, 665-673.

Schoener, T.W. (1967) The ecological significance of sexual dimorphism in size in the lizard Anolis conspersus. Science, 155, 474-477.

Schoener, T.W. (1969) Size patterns in West Indian Anolis lizards: I. Size and species diversity. Systematic Zoology, 18, 386-401.

Schoener, T.W. (1977) Competition and the niche. Biology of the Reptilia, vol. 7 (eds D.W. Tinkle \& C. Gans), pp. 35-136. Academic Press, New York, NY.

Schoener, T.W., Slade, J.B. \& Stinson, C.H. (1982) Diet and sexual dimorphism in the very catholic lizard genus, Leiocephalus, of the Bahamas. Oecologia, 53, 160-169.

Scott, S.N., Clegg, S.M., Blomberg, S.P., Kikkawa, J. \& Owens, I.P.F. (2003) Morphological shifts in island-dwelling passerines: the roles of generalist foraging and niche expansion. Evolution, 57, 2147-2156.

Selander, R.K. (1966) Sexual dimorphism and differential niche utilization in birds. Condor, 68, 113-151.

Shine, R. (1989) Ecological causes for the evolution of sexual dimorphism: a review of the evidence. Quarterly Review of Biology, 64, 419-461.
Simberloff, D., Dayan, T., Jones, C. \& Ogura, G. (2000) Character displacement and release in the small Indian mongoose, Herpestes javanicus. Ecology, 81, 2086-2099.

Slatkin, M. (1984) Ecological causes of sexual dimorphism. Evolution, 38, 622-630.

Smith, R.J. (1999) Statistics of sexual size dimorphism. Journal of Human Evolution, 36, 423-459.

Soule, M.E. (1966) Trends in insular radiation of a lizard. American Naturalist, 100, 47-64.

Stephens, P.R. \& Wiens, J.J. (2009) Evolution of sexual size dimorphisms in emydid turtles: ecological dimorphism, Rensch's rule, and sympatric divergence. Evolution, 63, 910-925.

Strong, D.R., Szyska, L.A. \& Simberloff, D. (1979) Tests of community-wide character displacement against null hypotheses. Evolution, 33, 897-913.

Stuart, Y.E. \& Losos, J.B. (2013) Ecological character displacement: glass half full or half empty? Trends in Ecology \& Evolution, 28, 402-408.

Szabo, P. \& Meszena, G. (2006) Limiting similarity revisited. Oikos, 112, 612-619.

Temeles, E.J., Miller, J.S. \& Rifkin, J.L. (2010) Evolution of sexual dimorphism in bill size and shape of hermit hummingbirds (Phaethornithinae): a role for ecological causation. Philosophical Transactions of the Royal Society of London B, 365, 1053-1063.

Temeles, E.J., Pan, I.L., Brennan, J.L. \& Horwitt, J.N. (2000) Evidence for ecological causation of sexual dimorphism in a hummingbird. Science, 289, 441-443.

Uetz, P. (2013) The reptile database, http://reptile-database.reptarium.cz, accessed June 2, 2013.

Valakos, E.D., Pafilis, P., Sotiropoulos, K., Lymberakis, P., Maragou, P. \& Foufopoulos, J. (2008) The Amphibians and Reptiles of Greece. Edition Chimaira, Frankfurt Am Main, Germany.

Van Valen, L.M. (1965) Morphological variation and the width of the ecological niche. American Naturalist, 99, 377-390.

Wilson, D.E. \& Mittermeier, R.A. (2009) Handbook of the Mammals of the World. 1. Carnivores. Lynx Edicions, Barcelona, Spain.

Wozencraft, W.C. (2005) Order Carnivora. Mammal Species of the World, 3rd edn (eds D.E. Wilson \& D.M. Reeder), pp. 532-628. The Johns Hopkins University Press, Baltimore.

Yasuma, S. (2004) Observations of a live Hose's Civet Diplogale hosei. Small Carnivore Conservation, 31, 3-5.

Yoder, A.D., Burns, M.M., Zehr, S., Delefosse, T., Veron, G., Goodman, S.M. et al. (2003) Single origin of Malagasy Carnivora from an African ancestor. Nature, 421, 734-737.

Zielinski, W.J., Duncan, N.P., Farmer, E.C., Truex, R.L., Clevenger, A.P. \& Barrett, R.H. (1999) Diet of fishers (Martes pennanti) at the southernmost extent of their range. Journal of Mammalogy, 80, 961-971.

Received 8 September 2013; accepted 3 May 2014

Handling Editor: Guarino Colli

\section{Supporting Information}

Additional Supporting Information may be found in the online version of this article.

Appendix S1 Institutional origins of the carnivore specimens used in this study

Appendix S2 Carnivores on islands

Appendix S3 Carnivore species, guild and family membership

Appendix S4 Lizard species richness and SSD on islands

Appendix S5 Intraspecific results: carnivores

Appendix S6 SSD and carnivore species richness, interspecific

Appendix S7 Intraspecific SSD of lizards on Aegean Sea islands 